\title{
Principles for the application of life cycle sustainability assessment
}

\author{
Sonia Valdivia ${ }^{1} \cdot$ Jana Gerta Backes ${ }^{2} \cdot$ Marzia Traverso $^{2} \cdot$ Guido Sonnemann $^{3} \cdot$ Stefano Cucurachi $^{4}$. \\ Jeroen B. Guinée ${ }^{4} \cdot$ Thomas Schaubroeck $^{5} \cdot$ Matthias Finkbeiner $^{6} \cdot$ Noemie Leroy-Parmentier $^{3} \cdot$ Cássia Ugaya $^{7}$. \\ Claudia Peña ${ }^{8} \cdot$ Alessandra Zamagni $^{9} \cdot$ Atsushi Inaba $^{10} \cdot$ Milena Amaral $^{11} \cdot$ Markus Berger $^{6} \cdot$ Jolanta Dvarioniene $^{12}$. \\ Tatiana Vakhitova $^{13} \cdot$ Catherine Benoit-Norris $^{14} \cdot$ Martina Prox $^{15} \cdot$ Rajendra Foolmaun $^{16} \cdot$ Mark Goedkoop $^{17}$
}

Received: 1 July 2021 / Accepted: 21 July 2021 / Published online: 18 August 2021

(c) The Author(s) 2021

\begin{abstract}
Purpose and context This paper aims to establish principles for the increased application and use of life cycle sustainability assessment (LCSA). Sustainable development (SD) encompassing resilient economies and social stability of the global system is growingly important for decision-makers from business and governments. The "17 SDGs" emerge as a high-level shared blueprint for peace, abundance, and prosperity for people and the planet, and "sustainability" for supporting improvements of products and organizations. A "sustainability" interpretation-successful in aligning stakeholders' understanding — subdivides the impacts according to a triple bottom line or three pillars: economic, social, and environmental impacts. These context and urgent needs inspired the LCSA framework. This entails a sustainability assessment of products and organizations in accordance with the three pillars, while adopting a life cycle perspective.

Methods The Life Cycle Initiative promotes since 2011 a pragmatic LCSA framework based on the three techniques: LCSA = environmental life cycle assessment (LCA) + life cycle costing (LCC) + social life cycle assessment (S-LCA). This is the focus of the paper, while acknowledging previous developments. Identified and reviewed literature shows challenges of addressing the three pillars in the LCSA framework implementation like considering only two pillars; not being fully aligned with ISO 14040; lacking interconnectedness among the three pillars; not having clear criteria for results' weighting nor clear results' interpretation; and not following cause-effect chains and mechanisms leading to an endpoint. Agreement building among LCSA experts and reviewing processes strengthened the consensus on this paper. Broad support and outreach are ensured by publishing this as position paper.

Results For harmonizing practical LCSA applications, easing interpretation, and increasing usefulness, consensed ten LCSA principles (10P) are established: understanding the areas of protection, alignment with ISO 14040, completeness, stakeholders' and product utility considerations, materiality of system boundaries, transparency, consistency, explicit trade-offs' communication, and caution when compensating impacts. Examples were provided based on a fictional plastic water bottle Conclusions In spite of increasing needs for and interest in SD and sustainability supporting tools, LCSA is at an early application stage of application. The 10P aim to promote more and better LCSA applications by ensuring alignment with ISO 14040, completeness and clear interpretation of integrated results, among others. For consolidating its use, however, more consensus-building is needed (e.g., on value-laden ethical aspects of LCSA, interdependencies and interconnectedness among the three dimensions, and harmonization and integration of the three techniques) and technical and policy recommendations for application.
\end{abstract}

Keywords Sustainability $\cdot$ Life cycle assessment $\cdot$ LCSA $\cdot$ Principles $\cdot$ Life cycle initiative

\section{Background}

Communicated by Martin Baitz.

Sonia Valdivia

sonia.valdivia@wrforum.org

Extended author information available on the last page of the article
Sustainable development is becoming increasingly important to support decision-making for business and government policies. For sustainable decision-making, a variety of interrelated, uncertain, and subjective problems need to 
be considered (Zanghelini et al. 2018). Sustainable development requires decision-makers to think beyond current economic structures and indicators, such as the gross domestic product (GDP), inducing resilient economies that monitor the well-being of countries without neglecting the social stability of the global system (Hoekstra 2019). This implies re-thinking economies based on inclusive and more sustainable pathways.

The 2030 Agenda for Sustainable Development (UN General Assembly 2015) provides a shared blueprint for peace, abundance, and prosperity for people and the planet. At its heart are the 17 Sustainable Development Goals (SDGs), which are an urgent call for action by all countries-developed and developing-in a global partnership (UN Department of Economic and Social Affairs 2015).

For sustainable development to be implemented effectively, performance measures are required. Sustainability is understood differently by different stakeholders and decision-makers. This complicates coordinated measurement, mapping, and improvement of products' and organizations' sustainability performance along their value chains and across regions (Arroyo et al. 2016; Valdivia et al. 2013; Zamagni 2012).

The Agenda 21 (UN 1992) built upon the Brundtland Report (1987) made an important contribution to the global discussion on sustainable development by emphasizing the problems of the north-south development divide and the need to link social and economic development with environmental protection. Without a clear point of origin, one of the more ubiquitous interpretations of sustainability subdivides the impacts according to three pillars: economic, social, and environmental impacts (Purvis et al. 2019). This was translated into the triple bottom line (TBL) by Elkington in 1999, whom later claimed in 2018 that the full potential of TBL has not been well understood nor implemented. He advocates for a new wave of deployment of TBL with the pace and scale needed to stop overshooting planetary boundaries. Moreover, Purvis et al. (2019) highlight that any rigorous operationalization of a sustainability framework requires an explicit description of what sustainability entails.

\section{Purpose of this position paper}

The aim of this position paper is to establish principles for the application and use of life cycle sustainability assessment (LCSA) by building on the best practice currently available. Furthermore, the purpose of this paper is to promote LCSA thinking worldwide.

\section{Life cycle sustainability assessment}

The context and urgent needs described have inspired the concept of the LCSA framework. This entails a sustainability assessment of products and organizations, originally coined in accordance with the three pillars (Kloepffer 2008), while adopting a life cycle perspective. The life cycle perspective spans from the extraction of resources, material production, manufacturing, logistics, use, maintenance, repairing, recovery of resources, and re-manufacturing, until the final disposal of waste. The advantage of LCSA is its system perspective and the identification of potential trade-offs between the three pillars.

Since 2011, the Life Cycle Initiative promotes a pragmatic LCSA framework (UNEP 2011), which was taken up by the community in the form of studies and papers of a diverse geographical and sectoral origin. Techniques to address each of the three pillars in the LCSA framework correspond to the environmental life cycle assessment (LCA) (built on ISO 14040: 2006; ISO 14044: 2006), life cycle costing (LCC) (SETAC 2011), and social life cycle assessment (S-LCA) (UNEP 2009, 2020).

While we acknowledge the developments in the past years, this position paper focuses on this pragmatic LCSA framework endorsed and promoted by the Life Cycle Initiative (Finkbeiner et al. 2010; Kloepffer 2008; UNEP 2011; Valdivia et al. 2013), for product-, service-, and organization-related applications. With this focus, we define LCSA as follows:

$L C S A=L C A+L C C+S-L C A$

The above formulation represents an operational approach in which the three methods are executed separately to the same case, and then, their outcomes are compared or aggregated using weighting. A recollection of developments within the past 12 years include many different conceptualizations of LCSA (Guinée 2015; Guinée et al. 2011; Heijungs et al. 2010; Neugebauer et al. 2015; Schaubroeck and Rugani 2017; Zamagni 2012 and Zamagni et al. 2013). Recently, another extension of LCSA has been developed by Weidema et al. (2020) to cover the indicators and targets of the UN Sustainable Development Goals.

The pragmatic LCSA framework, on which we focus, is especially dependent on the three separate methods, which have different levels of data availability and maturity (related to tools user-friendliness, methodological issues about the impact assessment phase, interpretation of results, reports' records availability); see Fig. 1 for a qualitative assessment). Nevertheless, the LCSA framework is globally accepted and the need for an applicable approach is constantly increasing (Traverso et al. 2012a, b). 
Fig. 1 Maturity levels and data availability of life cycle approaches (x-axis: progress/ development) maturity

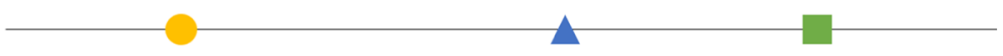

data availability
S-LCA

$\triangle \mathrm{LCC}$
LCA

\section{LCSA application: challenges}

Addressing the three pillars in harmonizing the LCSA framework implementation is not a trivial task, additionally leading to interpretation problems (Chen and Holden 2018; Traverso et al. 2012).

LCSA reports assessed (a sample of 165 LCSA papers were identified and analyzed, Leroy-Parmentier et al. 2021) show a diversity in the applications and challenges. For example, they may:

a consider only two pillars;

b base on approaches not fully aligned with the ISO 14040 framework;

c lack interconnectedness among three pillars;

d apply contradicting models and assumptions such as inconsistent system boundaries, ${ }^{1}$ preventing fair comparisons;

e not clearly explain and communicate assumptions and data chosen;

f not follow clear criteria for the definition of the functional unit and system boundaries, and for the selection of indicators;

g not follow cause-effect chains and mechanisms leading to an endpoint;

$\mathrm{h}$ not clearly define the target audiences and users of the LCSA results and disregard their goals, personal values, or cultural differences;

i present results with different levels of detail and background information for each pillar which make them hard to communicate and more difficult to understand especially for decision-makers who need them the most;

$\mathrm{j}$ apply arguable and non-transparent weighting of results linked to LCA, LCC, and S-LCA.

Thus, additional guidance is needed for harmonizing practical applications of LCSA, ease the interpretation, and increase the usefulness also for non-experts and decisionmakers at policy, business, and citizens level globally.

\footnotetext{
1 The system boundaries (SB) are defined as the union of all process units (PU) which are relevant at least for one of the three pillars: environmental, economic, and social.
}

Agreement building among LCSA experts and reviewing processes were established and implemented to strengthen the consensus on the topics addressed in this paper. It is expected that broad support and outreach will be ensured by publishing this as position paper of the Life Cycle Initiative.

\section{Principles for conducting an LCSA study}

To fill the gap for better-informed decision-making, and following the current state of the art, the following ten (10) principles are presented.

Note: Examples added for illustrating several principles are based on a fictional plastic water bottle.

1. Understanding of the areas of protection and impact pathways including the cause-effect mechanisms connecting inventory results to mid- and endpoints of an area of protection (AoP). ${ }^{2}$ If cause-effect chains and mechanisms are not sufficiently known nor advanced for implementing an LCSA, indicate the shortcomings which should be further enhanced by methods developers. If available, mid- and endpoint indicators shall be identified.

Example: In our example, human well-being (targeting the community residents where water is extracted from) is defined as the AoP. An impact pathway is established from the use of water as a natural resource via clean freshwater supply (offered to the community where the facility is located) to the well-being of the residents.

2. Alignment with the phases of ISO 14040, 2006 standard. LCSA shall consider the phases of goal and scope, inventory analysis, impact assessment, and interpretation, in accordance with this standard.

3. Completeness. This principle ensures that the LCSA covers all pillars. Furthermore, LCA, LCC, and S-LCA have to

\footnotetext{
2 The AoP and the endpoint are different in which the AoP can be a type of endpoint that represents a value and concern (such as human health, natural environment, natural resources, and man-made environment). The endpoint represents then a variable of that concern that can support a quantifiable representation of the AoP.
} 
be complete as well and cover all product life cycle stages or the entire value chains within the specified boundaries with a clear justification of any exclusions. Otherwise, the study shall not be called an LCSA. Life cycle thinking shall be the basic approach for considering the techniques (LCA, LCC, and S-LCA) and LCSA complete.

Example: Assessing only the carbon footprint and the costs along the life cycle of the plastic water bottle misses other environmental indicators and the analysis of the social pillar. In another example, only assessing the social impacts of one life cycle stage misses the environmental view. Both cases are considered incomplete LCSAs.

4. Consideration of the perspectives of key stakeholders. Studies shall not exclude specific societal groups. LCSA data collected shall serve the decision-making purposes of all identified stakeholders and users in terms of geographical reach and details and indicators covered.

Example: A study of a water bottle produced in India and sold in France should consider the differences in purchasing power, wages, and marginal utility of income for the workers in India when comparing to the marginal value of the product for the consumers in France.

5. Consideration of the product utility beyond the functional unit (co-benefits) ${ }^{3}$. This principle ensures a proper understanding of the product concerned through the definition of its core characteristics.

Example: A water bottling facility located in a poor area can have the co-benefit of making clean, piped water cheaply available for the local community that have hitherto not had piped water supply.

6. Materiality of the system boundaries ${ }^{4}$ ensures that relevant and significant unit processes that have impacts on one or more pillars of sustainability are within the system boundaries and are not excluded from the assessment.

\footnotetext{
${ }^{3}$ Product utility refers to the perception of the consumer in regard to what the product provides, besides its function (the capacity of a good to satisfy a need). This appreciation is linked with his/her cultural and social values, as well as his/her desires and satisfaction. Product utility can be identified in technical terms (quality, functionality, etc.) or in social terms (convenience, prestige, etc.) (UNEP 2020).

${ }^{4}$ The system boundaries (SB) are defined as the union of all process units (PU) which are relevant at least for one pillar of the sustainability.
}

Example: For the example of the plastic water bottle, the system boundaries reach from the plastics granulates to the bottles recycling phase. From the social and environmental perspectives, waste plastic collection is important and from the economic perspective, the administrative offices of the facility.

7. Consistency ensures the non-contradictory use or selection of system boundaries, methods, impact categories, models, data, and assumptions to allow for meaningful comparisons of the datasets produced over time.

8. Transparency ensures the open, comprehensive, understandable presentation of methods, data sources, assumptions, cause-effect chains, criteria for selection and implementation, and interpretation (and weighting criteria, if applicable), and limitations - thus allowing others to understand the assessment and reproduce it.

9. Explicit communication of trade-offs ensures that decisions based on LCSA results are more consciously made, rationally defensible, and balanced from the three pillars perspective. Trade-offs shall also respect local values, ethics, culture, professional stand, etc.

Example: The low-price structure of the water bottle is based on the low recyclability grade of the plastic bottle and low-cost access to water sources (such as groundwater). Under a business-as-usual scenario, the use of groundwater is compromising the water availability for local communities. This trade-off needs to be addressed in the study and its communication.

10. Caution when compensating negative and positive impacts within a pillar or among the three pillars. This principle prevents misinterpretation or misuse of the results in decision-making. Hence, at least, present negative and positive impacts separately, and report weighting principles transparently, if applied.

Example: For the plastic bottle example, 100 new jobs were created to promote the recycling of plastic water bottles. On the other hand, gender pay gaps in administrative-related positions have been identified. The positive aspects of 100 new jobs created in an area with prior unemployment cannot, according to some viewpoints, compensate for the gender pay gaps identified.

\section{Outlook for more LCSA application}

To advance the application and research of LCSA, the following aspects need further attention: 
Expand and improve the application of LCSA by taking into consideration the above principles. This will create more and better LCSA applications.

Identify relevant other approaches for LCSA applications, such as the " 6 capitals" framework which covers the following capital areas and is emergingly used for integrated reporting: "financial," "manufactured," "intellectual," "natural," "human," and "social" (Capitals Coalition 2016).

Consensus-building and dialogue on value-laden ethical aspects of LCSA, its goal, and the interdependencies and interconnectedness among the three dimensions. Throughout this process, interdisciplinary collaboration and involvement of key stakeholders contributing to LCSA globally will facilitate the engagement of potential decision-makers.

The harmonization and/or integration of the three individual assessments (LCA, LCC, and S-LCA) within LCSA. This comes timely with the S-LCA guidelines (2020) that complements the LCA and LCC experiences. Where cause-effect chains and mechanisms for implementing an LCSA are insufficient or unknown, method developers are called to contribute with their development or enhancement.

Additional technical and policy recommendations to conduct LCSA, for enhanced rigor and reproducibility of results.

We hope that the above principles and areas of attention can increase the pace and scale of LCSA development and implementation in the different regions, sectors, and products around the world in support of the Sustainable Development Goals and sustainability assessments.

Acknowledgements The Life Cycle Initiative acknowledges the reviewers who were part of the internal review process of this paper: Members of the Steering Committee of the Life Cycle Initiative and the leaders of the Life Cycle Initiative Project on "Linking the SDG to LCA," who are not co-authors.

Funding Open Access funding enabled and organized by Projekt DEAL.

Open Access This article is licensed under a Creative Commons Attribution 4.0 International License, which permits use, sharing, adaptation, distribution and reproduction in any medium or format, as long as you give appropriate credit to the original author(s) and the source, provide a link to the Creative Commons licence, and indicate if changes were made. The images or other third party material in this article are included in the article's Creative Commons licence, unless indicated otherwise in a credit line to the material. If material is not included in the article's Creative Commons licence and your intended use is not permitted by statutory regulation or exceeds the permitted use, you will need to obtain permission directly from the copyright holder. To view a copy of this licence, visit http://creativecommons.org/licenses/by/4.0/.

\section{References}

Arroyo P, Fuenzalida C, Albert A, Hallowell MR (2016) Collaborating in decision making of sustainable building design: an experimental study comparing CBA and WRC methods. Energy and Buildings 128:132-142. https://doi.org/10.1016/j.enbuild. 2016.05.079

Bruntland GH (1987) Report of the World Commission on Environment and Development: our common future. United Nations General Assembly document A/42/427

Capitals Coalition (CC) (2016) Natural capital protocol. Available: www.naturalcapitalcoalition.org/protocol

Chen W, Holden NM (2018) Tiered life cycle sustainability assessment applied to a grazing dairy farm. J Clean Prod 172:11691179. https://doi.org/10.1016/j.jclepro.2017.10.264

Elkington J (1999) Cannibals with forks: the triple bottom line of 21 st century business. Capstone

Elkington J (2018) 25 years ago I coined the phrase "Triple Bottom Line." Here's why it's time to rethink it. Retreived from https:// hbr.org/2018/06/25-years-ago-i-coined-the-phrase-triple-bottomline-heres-why-im-giving-up-on-it

Finkbeiner M, Schau EM, Lehmann A, Traverso M (2010) Towards Life Cycle Sustainability Assessment. Sustainability 2(10):3309-3322. https://doi.org/10.3390/su2103309

Guinée JB (2015) Life cycle sustainability assessment: what is it and what are its challenges? In R. Clift \& A. Druckman (Eds.), Taking Stock of Industrial Ecol (1-362). https://doi.org/10.1007/ 978-3-319-20571-7

Guinée JB, Heijungs R, Huppes G, Zamagni A, Masoni P, Buonamici R, Rydberg T (2011) Life cycle assessment: past, present, and future. Environ Sci Technol 45(1):90-96. https://doi.org/10. 1021/es101316v

Heijungs R, Huppes G, Guinée JB (2010) Life cycle assessment and sustainability analysis of products, materials and technologies. Toward a scientific framework for sustainability life cycle analysis. Polym Degradation Stab 95(3), 422-428. https://doi.org/10. 1016/j.polymdegradstab.2009.11.010

Hoekstra R (2019) Replacing GDP by 2030: Towards a common language for the well-being and sustainability community. Cambridge University Press, Cambridge. https://doi.org/10.1017/ 9781108608558

ISO 14040 (2006) Environmental management - life cycle assessment - principles and framework

Kloepffer W (2008) Life cycle sustainability assessment of products (with Comments by Helias A. Udo de Haes, p. 95). Intern J Life Cycle Assess 13(2), 89-95. https://doi.org/10.1065/ lca2008.02.376

Neugebauer S, Martinez-Blanco J, Scheumann R, Finkbeiner M (2015) Enhancing the practical implementation of life cycle sustainability assessment - Proposal of a Tiered approach. J Clean Prod 102:165-176. https://doi.org/10.1016/j.jclepro. 2015.04.053

Leroy-Parmentier N, Valdivia S, Backes J, Traverso M (2021) Alignment of case studies with the Life Cycle Initiative LCSA's principles. Manuscript to be submitted for publication, University of Bordeaux, Institute of Molecular Sciences, CyVi Group, France

Purvis B, Mao Y, Robinson D (2019 Three pillars of sustainability: in search of conceptual origins. Sustain Sci 14:681-695

Schaubroeck T, Rugani B (2017) A revision of what life cycle sustainability assessment should entail: towards modeling the net impact on human well-being. J Ind Ecol 21(6):1464-1477. https://doi.org/10.1111/jiec. 12653

SETAC (2011) Environmental life cycle costing: a code of practice (T. Swarr, D. Hunkeler, W. Klöpffer, H.L. Pesonen, A. Ciroth, A. Brent, \& R. Pagan, eds.) 
Traverso M, Asdrubali F, Francia A, Finkbeiner M (2012a) Towards life cycle sustainability assessment: an implementation to photovoltaic modules. Int J Life Cycle Assess 17(8):1068-1079. https://doi.org/10.1007/s11367-012-0433-8

Traverso M, Finkbeiner M, Jørgensen A, Schneider L (2012b) Life cycle sustainability dashboard. J Ind Ecol 16:680-688. https:// doi.org/10.1111/j.1530-9290.2012.00497.x

UN, (1992) Agenda 21, Rio Declaration, Forest Principles. United Nations, New York

UN Department of Economic and Social Affairs (2015) Sustainable development. The 17 Goals. Retrieved November 27, 2020, from https://sdgs.un.org/goals

UN General Assembly (2015) Transforming our world: the 2030 Agenda for Sustainable Development. Retrieved November 27, 2020, from https://www.refworld.org/docid/57b6e3e44.html

UNEP (2009) Guidelines for social life cycle assessment of products.

UNEP (2011) Towards a life cycle sustainability assessment. DTI/1412/PA

UNEP (2020 Guidelines for social life cycle assessment of products. Management, 15(2), 104. Retrieved from http://www.unep.fr/ shared/publications/pdf/DTIx1164xPA-guidelines_sLCA.pdf
Valdivia S, Ugaya CML, Hildenbrand J, Traverso M, Mazijn B, Sonnemann G (2013) A UNEP/SETAC approach towards a life cycle sustainability assessment - our contribution to Rio+20. Int J Life Cycle Assess 18(9):1673-1685. https://doi.org/10.1007/ s11367-012-0529-1

Weidema B, Goedkoop M, Meijer E, Harmens R (2020) LCA-based assessment of the Sustainable Development Goals. Retreived from https://lca-net.com/files/Report-SDGs-Aug-2020.pdf

Zamagni A (2012) Life cycle sustainability assessment. Int J Life Cycle Assess 17(4):373-376. https://doi.org/10.1007/s11367-012-0389-8

Zamagni A, Pesonen HL, Swarr T (2013) From LCA to life cycle sustainability assessment: concept, practice and future directions. Int J Life Cycle Assess 18(9):1637-1641. https://doi.org/10.1007/ s11367-013-0648-3

Zanghelini GM, Cherubini E, Soares SR (2018) How multi-criteria decision analysis (MCDA) is aiding life cycle assessment (LCA) in results interpretation. J Clean Prod 172:609-622. https://doi. org/10.1016/j.jclepro.2017.10.230

Publisher's Note Springer Nature remains neutral with regard to jurisdictional claims in published maps and institutional affiliations.

\section{Authors and Affiliations}

\section{Sonia Valdivia ${ }^{1}$ Jana Gerta Backes ${ }^{2}$ - Marzia Traverso ${ }^{2}$. Guido Sonnemann ${ }^{3}$. Stefano Cucurachi ${ }^{4}$. Jeroen B. Guinée ${ }^{4}$. Thomas Schaubroeck ${ }^{5}$. Matthias Finkbeiner ${ }^{6} \cdot$ Noemie Leroy-Parmentier $^{3}$ - Cássia Ugaya ${ }^{7}$. Claudia Peña $^{8} \cdot$ Alessandra Zamagni $^{9} \cdot$ Atsushi Inaba $^{10} \cdot$ Milena Amaral $^{11} \cdot$ Markus Berger $^{6} \cdot$ Jolanta Dvarioniene $^{12}$. Tatiana Vakhitova $^{13} \cdot$ Catherine Benoit-Norris $^{14} \cdot$ Martina Prox $^{15} \cdot$ Rajendra Foolmaun $^{16} \cdot$ Mark Goedkoop $^{17}$}

1 World Resources Forum Association, Leuphana University of Luneburg, Luneburg, Germany

2 Institute of Sustainability in Civil Engineering, RWTH Aachen University, Aachen, Germany

3 Institute of Molecular Sciences, CyVi Group, University of Bordeaux, Bordeaux, France

4 Institute of Environmental Sciences, Leiden University, Leiden, the Netherlands

5 Environmental Research \& Innovation, Luxembourg Institute of Science and Technology (LIST), Esch-sur-Alzette, Luxembourg

6 Institute of Environmental Technology, Technische Universität Berlin, Berlin, Germany

7 Federal University of Technology - Paraná, Curitiba, Brazil

8 ADDERE Research \& Technology, Santiago, Chile
9 Ecoinnovazione Spin-off, ENEA, Bologna, Italy

10 Japan Life Cycle Assessment Facilitation Centre, Tokyo, Japan

11 ESCP Business School, Berlin, Germany

12 Institute of Environmental Engineering, Kaunas University of Technology, Kaunas, Lithuania

13 Ansys Ltd, Cambridge, UK

14 NewEarth B, York, USA

15 iPoint-Systems GmbH, Reutlingen, Germany

16 Ministry of Environment and Sustainable Development, Port Louis, Mauritius

17 PRé Consultants, Amersfoort, the Netherlands 